\title{
What's in a word? A parametric study of semantic influences on visual word recognition
}

\author{
Gemma A. L. Evans • Matthew A. Lambon Ralph • \\ Anna M. Woollams
}

Published online: 19 January 2012

(C) Psychonomic Society, Inc. 2012

\begin{abstract}
To what extent does semantic information play a functional role in visual word recognition? Theories of word recognition vary in the importance assigned to semantic information in visual lexical decision, with past research suggesting that the nature of the foils is a crucial determinant of semantic reliance. Here, we explored the conditions under which semantic variables influence lexical decision. Normal readers performed visual lexical decision tasks in which imageability and semantic priming were manipulated, with nonword foils varying systematically in their orthographic and phonological similarity to the real words. The effects of imageability and semantic priming increased in magnitude as nonword foils became progressively more wordlike. These findings provide a clear illustration of the flexible use of semantic information to support normal visual word recognition.
\end{abstract}

Keywords Visual word recognition · Semantics ·

Imageability $\cdot$ Priming $\cdot$ Foil context

The fundamental purpose of the written word is to communicate meaning, but the necessity of semantic information for visual word recognition has been hotly debated in the neuropsychological literature (Blazely, Coltheart, \& Casey, 2005; cf. Dilkina, McClelland, \& Plaut, 2010; Rogers, Lambon

Electronic supplementary material The online version of this article (doi:10.3758/s13423-011-0213-7) contains supplementary material, which is available to authorized users.

G. A. L. Evans • M. A. Lambon Ralph • A. M. Woollams ( $\bowtie)$ Neuroscience and Aphasia Research Unit, School of Psychological Sciences, Zochonis Building, University of Manchester,

Brunswick Street,

Manchester M13 9PL, England, UK

e-mail: anna.woollams@manchester.ac.uk
Ralph, Hodges, \& Patterson, 2004). For localist models that incorporate an independent level of structural lexical representations (e.g., Coltheart, Rastle, Perry, Ziegler, \& Langdon, 2001), semantic information is not required to recognize a word, whereas for connectionist models that include only distributed orthographic representations (e.g., Harm \& Seidenberg, 2004), semantic information becomes necessary to support accurate word recognition under certain circumstances. Word recognition has been typically examined using lexical decision tasks in which participants are required to discriminate between real words and nonword foils. Using this task, a word has been recognized when a familiar letter string can be accurately differentiated from a novel one. The difficulty of this discrimination will vary according to the nature of the nonword foils used, becoming harder the more similar they are to words in terms of their orthographic and phonological properties. Due to the absence of structural lexical representations, it is a clear prediction of connectionist models that semantic effects must increase as the discrimination between words and foils becomes increasingly difficult to achieve on the basis of orthographic and phonological form. We tested this prediction here by examining the size of semantic effects across a parametric increase in discrimination difficulty achieved by making the nonword foils progressively more similar to words.

For localist models, such as DRC (Coltheart et al., 2001), lexical decision is made on the basis of activation of entries within the orthographic input lexicon. Although the corollary of this independent level of structural lexical representations is that semantic information is not necessary to recognize words, cascaded and interactive processing permits activation from the semantic system to feed back to the orthographic input lexicon via bidirectional excitatory and inhibitory connections (Coltheart et al., 2001, p. 214), producing meaning-level effects. As nonword foils become 
more wordlike in terms of their orthographic composition, they produce more activation of similar words in the orthographic input lexicon. When they are also homophonic with a known word, they increase activation of the orthographic input lexicon further through activation of their phonological form from the nonlexical route feeding back via the phonological output lexicon (Coltheart et al., 2001, pp. 230231). In each case, as the foils become more similar to the words, the discrimination becomes more difficult, meaning that a higher level of activation of a lexical entry is required for a "word" decision in order to avoid false alarms. This therefore delays the decision and increases the opportunity for feedback from semantics. Hence, localist models can accommodate an increase in semantic effects across foil type.

Within connectionist models, semantic information plays a crucial role in lexical decision if discriminations cannot be made using form-based information (Plaut, 1997; Seidenberg $\&$ McClelland, 1990) due to their use of distributed orthographic representations. Several possible mechanisms may account for semantic influences within connectionist models, depending on the assumed locus of the lexical decision. Harm and Seidenberg (2004) suggested that lexical decision could be based on the degree to which the external input matches the internally activated orthographic representation, which may be influenced by feedback from semantics (see also Pexman \& Lupker, 1999; Van Orden, Pennington, \& Stone, 1990). As orthographic and phonological overlap between words and foils increases, the internally generated orthographic representation for a foil becomes more similar to a known word (Harm \& Seidenberg, 2004, p. 709). A more conservative criterion requiring a closer match between representations must, therefore, be adopted to avoid false alarms, delaying decision and allowing greater opportunity for semantic feedback to influence orthographic activation, as per localist models.

An alternative to an orthographic basis for lexical decision has been proposed in the context of other connectionist models, where the decision is instead made on the basis of activation across all levels of the word recognition system. By this view, semantic activation will be weighted more heavily in the metric as discrimination difficulty increases and neither orthographic nor phonological information is sufficient to avoid false alarms (Dilkina et al., 2010; Plaut, 1997; Seidenberg \& McClelland, 1990). Other accounts have designated semantics as the locus of lexical decision when legal foils are used (Borowsky \& Besner, 1993; Plaut \& Booth, 2000). Since these proposals suggest that semantic activation feeds directly into the decision process, feedback mechanisms are therefore not required to explain the presence of semantic effects.

Previous investigations of foil type manipulations upon semantic effects in lexical decision have produced inconsistent results. One dimension used as a marker of semantic involvement in real-word decisions is imageability, which refers to the degree to which a word's referent evokes a mental image (e.g., HARP vs. HOPE). Another is semantic priming, where the benefit of presenting a target (e.g., $D O G$ ) with a related (e.g., cat), as opposed to an unrelated (e.g., cup), prime is assessed (Neely, 1991). Past research has indicated that imageability effects are not reliable with unpronounceable foils but are significant with pseudoword and pseudohomophone foils (James, 1975), although the difference in effect size between the latter two conditions was not examined. A significant increase in the size of the semantic priming effect when shifting from consonant string to pseudoword foils has been reported (Shulman \& Davidson, 1977), and while some have reported a similar increase for the change from pseudoword to pseudohomophone foils (Joordens \& Becker, 1997), others have failed to observe any significant change (Lupker $\&$ Pexman, 2010) or have even reported a reduction (Milota Widau, McMickell, Juola, \& Simpson, 1997; Yap, Tse, \& Balota, 2009), contrary to what would be expected according to a connectionist account.

Clarification of the effect of foil type manipulations upon semantic influences in lexical decision is therefore clearly required, particularly with regard to whether semantic contributions increase across legal pseudoword and pseudohomophone foils. The goal of the present study was to conduct, for the first time, a parallel manipulation of the intraword dimension of imageability and the interword dimension of semantic priming, using the same parametric variation of discrimination difficulty across consonant string, pseudoword, and pseudohomophone foils, whereby there is a progressive increase in the orthographic and phonological similarity of the nonword foils to the real words. To the extent that connectionist models provide a viable account of visual word recognition, a significant increase in the magnitude of both semantic effects across foil types should be observed.

\section{Method}

\section{Design}

Each participant performed two lexical decision blocks, each of which contained a within-participants manipulation of the semantic markers of imageability and semantic priming. Order of block completion was counterbalanced between participants. Participants performed lexical decisions in the context of consonant string, pseudoword, or pseudohomophone foils; hence, foil type was manipulated between participants. While foil manipulations were critical to ensure the parametric 
increase in decision difficulty, the key effects of interest were the magnitude of the semantic effects observed across the foil types.

\section{Participants}

Seventy-two undergraduate students participated. All reported that they had no identified reading disorders and that English was their first language.

\section{Stimuli}

Imageability Each participant was presented with 80 real words and 80 nonword foils. The 80 real words were monosyllabic, three- to five-letter, low-frequency English words. Imageability ratings taken from the Cortese and Fugett (2004) database were used to select 40 low-imageability words (e.g., $O W E$ ), and 40 high-imageability words (e.g., $F U R$ ), matched pairwise on letter length. Three types of foil stimuli were created: pseudohomophones, pseudowords, and consonant strings. Eighty orthographically legal pseudohomophones were created, 40 of which had lowimageability basewords (e.g., $F E A$ [from $F E E$ ]) and 40 of which had high-imageability basewords (e.g., ZEW [from $Z O O]$ ). For each pseudohomophone a letter was replaced to create 80 orthographically legal, pronounceable pseudoword foils (e.g., FET), and vowels were replaced with consonants to create 80 orthographically illegal, unpronounceable consonant strings (e.g., FJK).

High- and low-imageability items had mean ratings of $6.11(S D=0.47)$ and $2.72(S D=0.41)$, respectively, and did not differ significantly in terms of frequency, neighborhood size, or bigram frequency (see Table 1 in Supplementary Materials). As was expected, the consonant strings did differ from the words on neighborhood size and bigram frequency, $F(1,78)=133.04, p<.001$, and $F(1,78)=80.05, p<.001$, respectively, but the pseudoword and pseudohomophone foils were comparable to the words on these dimensions (see Table 2 in Supplementary Materials). A full listing of imageability stimuli is provided in Tables 3, 4, and 5 in Supplementary Materials.

Semantic priming Each participant was presented with an additional 80 real words and 80 nonword foils, plus 160 primes, none of which were featured in the imageability set. The 80 real words were monosyllabic, three- to five-letter, low-frequency English words. Related primes for the 80 real-word targets were selected using the Maki (2008) database. The real-word targets were split into two lists and the related primes (e.g., wood-LOG) were shuffled to create unrelated items (e.g., oven-LIP). This resulted in two versions of the task for each foil type, the presentation of which was counterbalanced across participants. Again, three foil types were created: pseudohomophones, pseudowords, and consonant strings. Eighty orthographically legal pseudohomophones were created, and 80 prime words related to the pseudohomophone baseword were selected from the database. Again the pseudohomophones were split into two lists, and the related primes (e.g., key-LOK [from $L O C K]$ ) were shuffled to create unrelated items (e.g., car-DET [from $D E B T]$ ). Eighty orthographically legal pseudoword foils and 80 orthographically illegal, unpronounceable consonant strings were created in the same way as for the imageability set and were presented with the corresponding primes (e.g., $k e y-B O K, k e y-B P K)$.

The two lists of target words did not differ significantly on imageability, frequency, neighborhood size, or bigram frequency (see Table 6 in Supplementary Materials). As was expected, the consonant strings did differ from the words on neighborhood size and bigram frequency, $F(1,78)=175.33$, $p<.001$, and $F(1,78)=32.63, p<.001$, respectively, but the pseudoword and pseudohomophone foils were comparable to the words on these dimensions (see in Table 7 in Supplementary Materials). A full listing of semantic priming stimuli is provided in Tables 8, 9 and 10 in Supplementary Materials.

\section{Procedure}

Participants performed a yes/no lexical decision task. Stimuli were presented using DMDX (Forster \& Forster, 2003), and responses were made using a button box. Letter strings were presented in white uppercase 26-point font on a black background. On each trial, a fixation cross was presented in the center of the screen for $500 \mathrm{~ms}$ before a letter string was shown and remained visible until a response was made. Participants performed a block of 20 practice trials, followed by 160 experimental trials presented in a single block in a random order that was generated anew for each participant. For the semantic priming task, a prime word was presented in lowercase in the center of the screen for $500 \mathrm{~ms}$ immediately prior to presentation of the uppercase letter string.

\section{Results}

Correct reaction times and percentages of errors for nonword foil and real-word responses were analyzed, with responses over $3,500 \mathrm{~ms}$ removed from the analysis $(<0.05 \%$ trials in total $)$.

Imageability

The effectiveness of the foil type manipulation can be seen in the rejection times and false alarm rates for the foils: $562 \mathrm{~ms} / 1.30 \%$ for consonant strings rose to $812 \mathrm{~ms} / 6.46 \%$ 
for pseudowords and again to $1,038 \mathrm{~ms} / 12.14 \%$ for pseudohomophones. ANOVAs treating foil type as a betweenparticipants $\left(F_{1}\right)$ and within-items $\left(F_{2}\right)$ factor confirmed that as foils became increasingly wordlike, nonword responses became significantly slower $\left[F_{1}(2,69)=34.30, p<.001\right.$, $\eta^{2}=.50 ; F_{2}(2,158)=460.84, p<.001, \eta^{2}=.85 ;$ $\left.\min F^{\prime}(2,79)=31.92, p<.001\right]$ and less accurate $\left[F_{1}(2,69)=17.20, p<.001, \eta^{2}=.33 ; F_{2}(2,158)=29.93\right.$, $\left.p<.001, \eta^{2}=.23 ; \min F^{\prime}(2,150)=10.92, p<.001\right]$.

The reaction time and error data for real words presented in Fig. 1 also reflect the increase in discrimination difficulty due to foil type. The 2 (within participants/within items: imageability) $\times 3$ (between participants/within items: foil type) ANOVAs performed on real-word responses confirmed a significant imageability effect in reaction times $\left[F_{1}(1,69)=\right.$ $56.31, p<.001, \eta^{2}=.45 ; F_{2}(1,39)=19.21, p<.001, \eta^{2}=.33$; $\left.\min F^{\prime}(1,66)=14.32, p<.001\right]$ and errors $\left[F_{1}(1,69)=78.96\right.$, $p<.001, \eta^{2}=.53 ; F_{2}(1,39)=13.38, p<.001, \eta^{2}=.26$; $\left.\min F^{\prime}(1,52)=11.44, p<.001\right]$. As nonword foils became more wordlike, responses were slower $\left[F_{1}(2,69)=13.55\right.$, $p<.001, \eta^{2}=.28 ; F_{2}(2,78)=171.94, p<.001, \eta^{2}=.82$;
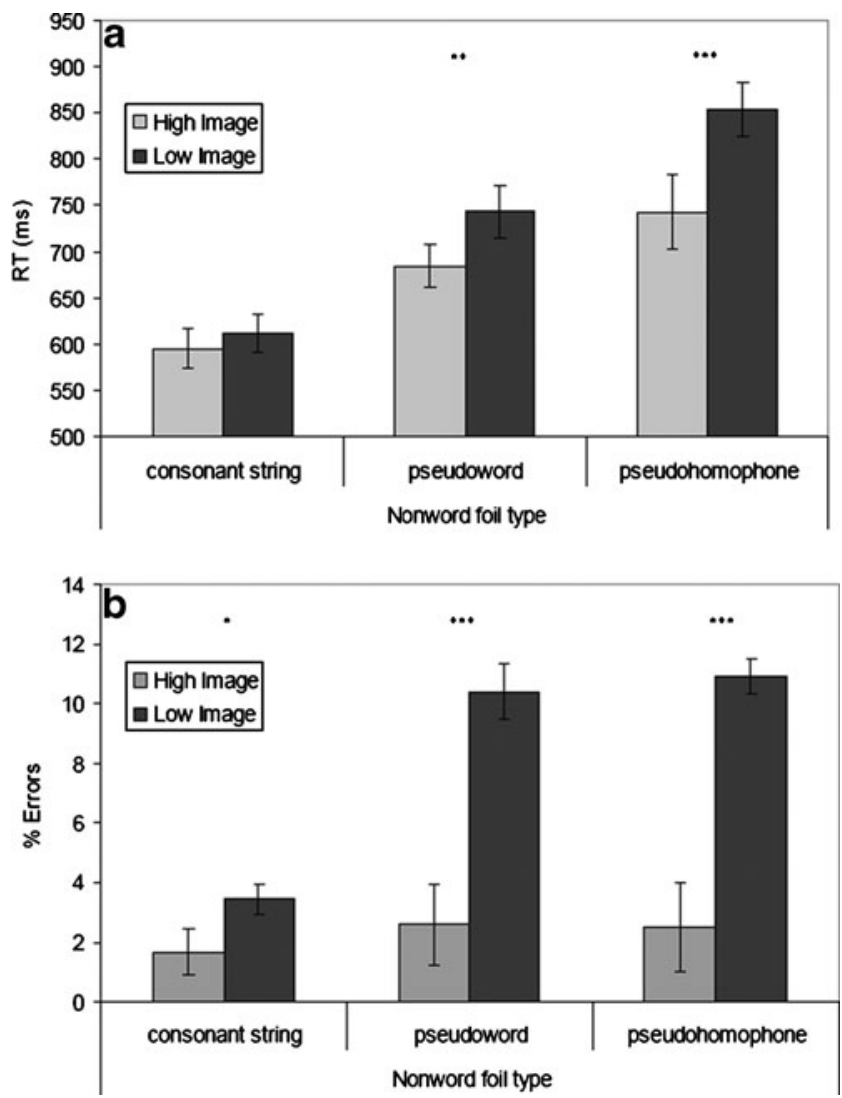

Fig. 1 Mean reaction times (a) and errors (b) for words of high imageability (e.g., $F U R$ ) and low imageability (e.g., $O W E$ ) in the context of consonant strings (e.g., FJK), pseudowords (e.g., FET), and pseudohomophones (e.g., FEA). Error bars represent \pm 1 SEM. Asterisks denote significance level of within-subjects $t$-tests of the imageability effect: ${ }^{*} p<.05,{ }^{* *} p<.01,{ }^{* * *} p<.001$ $\left.\min F^{\prime}(2,80)=12.56, p<.001\right]$ and less accurate $\left[F_{1}(2,69)=\right.$ $8.22, p<.01, \eta^{2}=.19 ; F_{2}(2,78)=12.77, p<.001, \eta^{2}=.24$; $\left.\min F^{\prime}(2,136)=5.00, p<.01\right]$. Critically, as nonword foils became more wordlike, the size of the imageability effect increased in reaction times $\left[F_{1}(2,69)=10.84, p<.001\right.$, $\eta^{2}=.24 ; F_{2}(2,78)=14.64, p<.001, \eta^{2}=.27 ; \min F^{\prime}(2,141)=$ $6.23, p<.01]$ and errors $\left[F_{1}(2,69)=9.89, p<.001, \eta^{2}=.22\right.$; $F_{2}(2,78)=7.80, p<.001, \eta^{2}=.17 ; \min F^{\prime}(2,147)=4.36$, $p<.05]$. Specifically, the $16-\mathrm{ms}$ and $1.77 \%$ imageability effect with consonant strings rose significantly to a 59-ms and $7.81 \%$ effect with pseudowords $\left[t_{1}(46)=2.28, p<.05\right.$; $t_{2}(39)=3.13, p<.01 ; t_{1}(46)=4.10, p<.001 ; t_{2}(39)=3.61$, $p<.001]$ and significantly increased again to a $111-\mathrm{ms}$ effect with pseudohomophones $\left[t_{1}(46)=2.23, p<.05\right.$; $\left.t_{2}(39)=2.72, p<.01\right]$, although the increase to $8.44 \%$ did not prove reliable.

\section{Semantic priming}

Again, the effectiveness of the foil type manipulation can be seen in the rejection times and false alarm rates for the foils: $557 \mathrm{~ms} / 1.98 \%$ for consonant strings rose to $718 \mathrm{~ms} / 6.30 \%$ for pseudowords and again to $902 \mathrm{~ms} / 6.72 \%$ for pseudohomophones. ANOVAs treating foil type as a betweenparticipants $\left(F_{1}\right)$ and within-items $\left(F_{2}\right)$ factor confirmed that as foils became increasingly wordlike, nonword responses became significantly slower $\left[F_{1}(2,69)=31.06, p<.001\right.$, $\eta^{2}=.47 ; F_{2}(2,158)=377.22, p<.001, \eta^{2}=.83$; $\left.\min F^{\prime}(2,81)=28.70, p<.001\right]$ and less accurate $\left[F_{1}(2,69)=6.72, p<.01, \eta^{2}=.16 ; F_{2}(2,158)=9.97\right.$, $\left.p<.001, \eta^{2}=.11 ; \min F^{\prime}(2,150)=4.01, p<.05\right]$.

The reaction time and error data for real words presented in Fig. 2 also evidences the increase in discrimination difficulty due to foil type. Two (within participants/within items: priming) $\times 3$ (between participants/within items: foil type) ANOVAs performed on real-word responses confirmed significant priming effects in reaction times $\left[F_{1}(1,69)=35.11, p<.001, \eta^{2}=.34 ; F_{2}(1,79)=26.61\right.$, $\left.p<.001, \eta^{2}=.25 ; \min F^{\prime}(1,147)=15.14, p<.001\right]$ and errors $\left[F_{1}(1,69)=17.76, p<.001, \eta^{2}=.21 ; F_{2}(1,79)=11.18\right.$, $\left.p<.001, \eta^{2}=.12 ; \min F^{\prime}(1,144)=6.86, p<.01\right]$. Real-word responses in the context of increasingly wordlike nonword foils were slower $\left[F_{1}(2,69)=7.99, p<.01, \eta^{2}=.19\right.$; $F_{2}(2,158)=133.38, p<.001, \eta^{2}=.63 ; \min F^{\prime}(2,77)=7.54$, $p<.01]$ and less accurate $\left[F_{1}(2,69)=3.97, p<.05, \eta^{2}=.10\right.$; $F_{2}(2,158)=4.89, p<.01, \eta^{2}=.06 ; \min F^{\prime}(2,176)=2.19$, $p<.11]$. Crucially, as nonwords became increasingly wordlike, the magnitude of the semantic priming effect increased in reaction times $\left[F_{1}(2,69)=6.83, p<.01, \eta^{2}=.17\right.$; $F_{2}(2,158)=6.69, p<.01, \eta^{2}=.08 ; \min F^{\prime}(2,194)=3.38$, $p<.05]$ and errors $\left[F_{1}(2,69)=4.92, p<.01, \eta^{2}=.13\right.$; $F_{2}(2,158)=4.67, p<.01, \eta^{2}=.06 ; \min F^{\prime}(2,196)=2.40$, $p<.09$ ]. Specifically, the $8-\mathrm{ms}$ and $0.10 \%$ priming effect with 

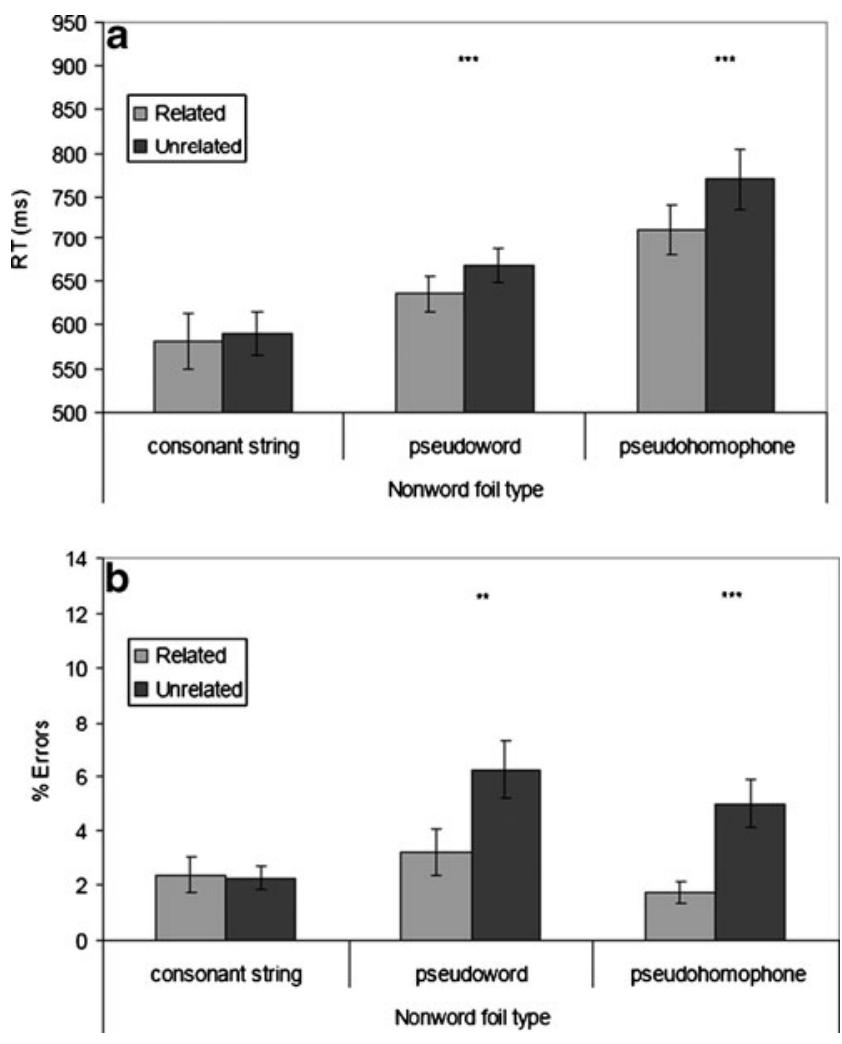

Fig. 2 Mean reaction times (a) and errors (b) for words preceded by related primes (e.g., wood-LOG) and unrelated primes (e.g., oven-LIP) in the context of consonant strings (e.g., key-BPK), pseudowords (e.g., key-BOK), and pseudohomophones (e.g., key-LOK). Error bars represent $\pm 1 S E M$. Asterisks denote significance level of withinsubjects $t$-tests of the priming effect: ${ }^{*} p<.05,{ }^{* *} p<.01,{ }^{* * *} p<.001$

consonant strings rose to a 32-ms and 3.02\% effect with pseudowords $\left[t_{1}(46)=1.81, p=.07 ; t_{2}(79)=1.74, p=.08\right.$; $\left.t_{1}(35)=2.65, p<.05 ; t_{2}(79)=-2.51, p<.05\right]$ and significantly increased again to a 59-ms effect with pseudohomophones $\left[t_{1}(46)=2.07, p<.05 ; t_{2}(79)=2.00, p<.05\right]$, although the increase to $3.23 \%$ did not prove reliable.

\section{Discussion}

The present results indicate, for the first time, a parallel parametric increase in the magnitude of the semantic effects of imageability and semantic priming as decision difficulty and reaction times increased across consonant string, pseudoword, and pseudohomophone foil contexts. Put simply, as decisions became harder and, therefore, slower, the advantage for high- over low-imageability words and for related over unrelated primes increased significantly. Although it might be argued that semantic effects are minimized with illegal foils, since the participants may base their decision on a very shallow level of stimulus analysis, the increase in both imageability and semantic priming effects also held across the transition from pseudowords to pseudohomophones.
This result would seem to rule out models where legal nonword foils invoke a simple categorical shift to a semantic locus for decision and semantic priming is envisaged to affect threshold consistently across processing (Borowsky \& Besner, 1993).

Several previous investigations have failed to find increased effects of semantic priming in pseudohomophone, relative to pseudoword, conditions, with this pattern observed in studies using a between-participants manipulation such as ours (Milota et al., 1997; Yap et al., 2009) and also those adopting a within-participants approach (Lupker \& Pexman, 2010). An examination of rejection times for pseudoword/ pseudohomophone foils across these previous studies reveals that they all show a smaller increase than the $718 \mathrm{~ms} / 902 \mathrm{~ms}$ observed for the semantic priming foils used here $(834 \mathrm{~ms} /$ 755 ms, Milota et al., 1997; 678 ms/709 ms, Yap et al., 2009; 681 ms/719 ms, Lupker \& Pexman, 2010). Notably, our pseudowords and pseudohomophones had considerably higher orthographic neighborhood size and/or bigram frequency than did those used previously. Although this was equally true for the pseudowords and the pseudohomophones, it seems likely that when pseudohomophones are of high orthographic familiarity, this allows more rapid activation of their associated phonological code, which in turn would make the rejection decision more difficult.

Given that we observed larger semantic effects with more wordlike foils at longer decision latencies, our results fit well within models of word recognition that assume an orthographic level for lexical decision and allow for feedback from the semantic level. Nevertheless, there had yet to be any explicit simulation semantic influences in visual lexical decision across foil type. For localist models (Coltheart et al., 2001; Davis, 2010; Grainger \& Jacobs, 1996), our results clearly indicate the need for a realistic implementation of the semantic system if they are to accurately simulate the process of lexical decision. For connectionist models that have incorporated some implementation of the semantic system, our results highlight the need to implement an explicit mechanism for making lexical decision. This may be based on orthographic activation that is sensitive to feedback from the semantic level (e.g., Harm \& Seidenberg, 2004), or alternatively, it may take the form of a flexible weighted metric of activation across all levels that is determined by the properties of the nonword foils (e.g., Plaut, 1997). Our empirical results provide a target data set that can be used to assess the adequacy of future computational simulations of lexical decision performance.

In the present study, larger semantic effects were seen at longer response latencies. Yet several recent electrophysiological investigations have suggested that semantic processing actually initiates very rapidly during the course of word recognition, with evidence of imageability and semantic priming effects being observed during silent reading tasks 
within $150 \mathrm{~ms}$ of stimulus onset (Sysoeva, Ilyuchenok, \& Ivanitsky; 2007; Wirth et al., 2008). Such early semantic processing has also been reported in ERPs during lexical decision tasks. Using pronounceable pseudoword foils, Hauk, Davis, Ford, Pulvermüller, and Marslen-Wilson (2006) found evidence of orthographic influences at $100 \mathrm{~ms}$ after stimulus onset, followed rapidly by semantic coherence effects at $160 \mathrm{~ms}$. Similarly, using MEG and fMRI recording during lexical decision with pronounceable katakana pseudoword foils, Fujimaki et al. (2009) found evidence of orthographic processing in ventral occipital-temporal regions at 100 $150 \mathrm{~ms}$ after stimulus onset, soon followed by evidence of semantic processing at $200 \mathrm{~ms}$ within the left anterior temporal area, which activated concurrently with phonological processing in left posterior superior temporal regions.

Given how early semantic effects emerge in electrophysiological measures, why then did we not find significant semantic effects in behavior in the consonant string foil conditions? In this regard, it is worth noting that there has yet to be any electrophysiological study that considers semantic influences upon lexical decision in the context of different types of foils, since all those reported thus far have used pronounceable pseudoword foils, and it was under these conditions that we saw significant semantic influences in the present study. It therefore remains to be seen whether such early electrophysiological semantic effects will be observed in the context of illegal foils.

In summary, our results provide a clear illustration of how semantic activation can be used flexibly to support visual word recognition across variations in task difficulty corresponding to different foil contexts. Whether this flexibility is reflected at the neural level remains to be determined, but recent neuroimaging (Hon, Thompson, Siagla, \& Duncan, 2009) suggests that recurrent feedback connections could permit task requirements to modulate the influence of semantic activation upon the very earliest stages of word recognition.

\section{References}

Blazely, A. M., Coltheart, M., \& Casey, B. J. (2005). Semantic impairment with and without surface dyslexia: Implications for models of reading. Cognitive Neuropsychology, 22, 695-717.

Borowsky, R., \& Besner, D. (1993). Visual word recognition: A multistage activation model. Journal of Experimental Psychology: Learning, Memory, and Cognition, 19, 813-840.

Coltheart, M., Rastle, K., Perry, C., Ziegler, J., \& Langdon, R. (2001). DRC: A dual route cascaded model of visual word recognition and reading aloud. Psychological Review, 108, 204-256.

Cortese, M. J., \& Fugett, A. (2004). Imageability ratings for 3,000 monosyllabic words. Behavior Research Methods, Instruments, \& Computers, 36, 384-387.

Davis, C. J. (2005). N-Watch: A program for deriving neighborhood size and other psycholinguistic statistics. Behavior Research Methods, Instruments, \& Computers, 37, 65-70.
Davis, C. J. (2010). The spatial coding model of visual word identification. Psychological Review, 117, 713-758.

Dilkina, K., McClelland, J. L., \& Plaut, D. C. (2010). Are there mental lexicons? The role of semantics in lexial decision. Brain Research, 1365, 66-81.

Forster, K. I., \& Forster, J. C. (2003). DMDX: A windows display program with millisecond accuracy. Behavior Research Methods, Instruments, \& Computers, 35, 116-124.

Fujimaki, N., Hayakawa, T., Ihara, A., Wei, Q., Montezuma, S., Terazono, Y., . . . Murata, T. (2009). Early neural activation for lexcio-semantic access in the left anterior temporal area analyzed by an fMRI-assisted MEG multidipole method. NeuroImage, 44, 1093-1102.

Grainger, J., \& Jacobs, A. M. (1996). Orthographic processing in visual word recognition: A multiple read-out model. Psychological Review, 103, 518-565.

Harm, M. W., \& Seidenberg, M. S. (2004). Computing the meanings of words in reading: Cooperative division of labor between visual and phonological processes. Psychological Review, 111, $662-720$.

Hauk, O., Davis, M. H., Ford, M., Pulvermüller, F., \& Marslen-Wilson, W. D. (2006). The time course of visual word recognition as revealed by linear regression analysis of ERP data. NeuroImage, 30, 1383-1400.

Hon, N., Thompson, R., Siagla, N., \& Duncan, J. (2009). Evidence for long-range feedback in target detection: Detection of semantic targets modulates activity in early visual areas. Neuropsychologia, 47, 1721-1727.

James, C. (1975). The role of semantic information in lexical decisions. Journal of Experimental Psychology: Human Perception and Performance, 104, 130-136.

Joordens, S., \& Becker, S. (1997). The long and short of semantic priming effects in lexical decision. Journal of Experimental Psychology: Human Perception and Performance, 23, 1083-1105.

Lupker, S. J., \& Pexman, P. M. (2010). Making things difficult in lexical decision: The impact of pseudohomophones and transposed-letter nonwords on frequency and semantic priming effects. Journal of Experimental Psychology: Learning, Memory, and Cognition, 36, 1267-1289.

Maki, W. S. (2008). A database of associative strengths from the strength-sampling model: A theory based supplement to the Nelson, McEvoy, and Schreiber word association norms. Behavior Research Methods, Instruments, \& Computers, 40, 232-235.

Milota, V. C., Widau, A. A., McMickell, M. R., Juola, J. F., \& Simpson, G. B. (1997). Strategic reliance on phonological mediation in lexical access. Memory \& Cognition, 25, 333-344.

Neely, J. H. (1991). Semantic priming effects in visual word recognition: A selective review of current findings and theories. In D. Besner \& G. W. Humphreys (Eds.), Basic processes in reading (pp. 264-336). Hillsdale, NJ: Erlbaum.

Pexman, P. M., \& Lupker, S. J. (1999). Ambiguity and visual word recognition: Can feedback explain both homophone and polysemy effects. Canadian Journal of Experimental Psychology, 53, 323-334.

Plaut, D. C. (1997). Structure and function in the lexical system: Insights from distributed models of word reading and lexical decision. Language \& Cognitive Processes, 12, 765-805.

Plaut, D. C., \& Booth, J. R. (2000). Individual and developmental differences in semantic priming: Empirical and computational support for a single-mechanism account of lexical processing. Psychological Review, 107, 786-823.

Rogers, T. T., Lambon Ralph, M. A., Hodges, J. R., \& Patterson, K. (2004). Natural selection: The impact of semantic impairment on lexical and object decisions. Cognitive Neuropsychology, 21, 331-352.

Seidenberg, M. S., \& McClelland, J. L. (1990). More words but no lexicon: Reply to Besner et al. (1990). Psychological Review, 97, $447-452$. 
Shulman, H. G., \& Davidson, T. C. B. (1977). Control properties of semantic coding in lexical decision task. Journal of Verbal Learning and Verbal Behavior, 16, 91-98.

Sysoeva, O. V., Ilyuchenok, I. R., \& Ivanitsky, A. M. (2007). Rapid and slow brain systems of abstract and concrete words differentiation. International Journal of Psychophysiology, 65, 272-283.

Van Orden, G. C., Pennington, B. F., \& Stone, G. O. (1990). Word identification in reading and the promise of subsymbolic psycholinguistics. Psychological Review, 97, 488-522.
Wirth, M., Horn, H., Koenig, T., Razafimandimby, A., Stein, M., Mueller, T., . . . Strik, W. (2008). The early context effect reflects activity in the temporo-prefrontal semantic system: Evidence from electrical neuroimaging of abstract and concrete word reading. NeuroImage, 42, 423-436.

Yap, M., Tse, C., \& Balota, D. A. (2009). Individual differences in the joint effects of semantic priming and word frequency as revealed by the RT distributional analyses: The role of lexical integrity. Journal of Memory and Language, 31, 303-325. 